\title{
LA HOUILLE
}

Revue Mensuelle des Forces et de lewrs

$13^{\mathrm{e}}$ Année. - Janvier r9 4 . - $\mathrm{N}^{\circ} \mathrm{x}$.

\section{CONGRES DE LA HOUILLE BLANGHE 1914 A LYON}

pendant l'Exposition Internationale urbaine

En même temps que nous annoncions, dans le dernier numéro de La Houille Blanche, la tenue à Lyon, au mois de septembre r $9^{\mathrm{r}}$ ḱ, d'un $\mathrm{II}^{\circ}$ Congrès de la Houille blanche, nous avions publié une liste des personnalités qui doivent composer le Comilé de Palronage et le Comilé d'Organisalion de ce Gongrès. La Chambre Syndicale des Forces Hydrauliques, qui s'est chargée de l'organisation de cc Congrès, nous a fait savoir que les listes en question ne sauraient être considérées comme officielles, el que son Conseil d'administration n'a encore arrêté aucune liste. Si, d'ailleurs, des décisions définitives étaient déjà prises à cet égard, le Conseil aurait eu soin, avant de publicr la composition de ces différents Comités, de s'assurer au préalable auprès des personnes dont les noms figurent sur les listes, qu'clles veulent bien accepter de prètcr leur concours et leur patronage à la Chambre Syndicale des Forces Hydrauliques.

Nous regrettons l'erreur où nous avons été bien involontairement conduits; nous sommes trop dévoués aux intérêts de la houille blanche et trop désireux d'assurer la collaboration que la Chambre Syndicale des Forces Hydrauliques veut bien nous demander en vue de ce Congrès, pour ne pas nous empresser de remeltre toutes les choses exactement au point.

\section{EXPOSITION DE LYON EN 1914}

L'Exposition Internationale Urbaine qui aura lieu à Lyon du $\mathrm{I}^{\text {er }}$ mai au $\mathrm{I}^{\mathrm{er}}$ novembre prochain, se compose de cinquante-deux Sections, dont une spécialement réservée à l'Electricité.

Cette section, la cinquante-et-unième, est présidée par M. Godinex, et a pour vice-président M. Londereau. Elle comporte quatre classes, savoir :

Crasse 281. - Houille blanche. - Rivières, réservoirs, barrages, vannes, canaux, tunnels, conduites forcées, etc., c'est-à-dire tous travaux du génie civil concernant l'aménagement des chutes. Projets, photographies, maquettes, etc.

M. LÉpine, administrateur-délégué de la Société de Fure et Morge, en sera le Président.

Classe 282. - Production de l'électricité. - Moteurs hydrauliques et thermiques, dynamos, alternateurs, etc., en un mot tout ce qui regarde le matériel d'équipement des usines génératrices.

M. Henrard, administrateur-délégué de la Société des Forces motrices du Rhône (Jonage) en sera le Président.

Crasse 282 bis. - Transport de l'électricité. - Câbles conducteurs, pylônes, supports, isolateurs, parafoudres, postes de couplage, transformateurs, etc., soit tous appareils concourant au transport de l'électricité, depuis l'usine génératrice jusque chez le consommateur.
Cettc classe sera présidéc par M. Loucneun, administratleur-délégué de la Compagnie électrique de la Loire et du Centre.

Ciasse 283. - Emplois de l'électricilé (autres que l'éclairage). - Elcctrométallurgie el électrochimic, fours, élcctrodes et outillages divers, moteurs ćlectriques, apparcils do ehauffage électrique, matériel permellant l'emploi de l'ćlectricité à l'agricullure el aux diverses industrics, etc., c'eslà-dire tous apparcils d'utilisation salu ceux concernant l'éclairago.

Le Président de celle classe sera M. Praton, adminislarleur de la Sociélé des Produits chimiques d'Alais el de li Camargue.

\section{CONSIDERATIONS PRATIQUES}

\section{SUR L'EXPLOITATION DES BREVETS D'INVENTION}

\section{Le projet de loi portant modification} de la loi du 5 juillet 1844 sur les Brevets d'invention

Nous avons exposé dans un précédent arlicle (1) les grandes lignes du projet déposé par le Gouvernement, modifiant la loi de I844 sur les Brevels d'invention, et indiqué les modificalions que ce projel apporte à une législation qui ne paraît plus en harmonie avec les tendances modernes, le développement de l'industrie el les conventions internationales intervenues en malière de propriété industrielle.

Ce projet renvoyé à l'examen de la Commission du Commerce et de l'Industrie vient d'être l'objet d'un intéressant rapport de M. Maurice Maunoury, dépulé.

La Commission accepte en principe le projet du Gonvernement : elle propose cependant d'apporter à la loi de $184 / 4$ un certain nombre de modifications non prévues au projet, telles nolamment que la prolongation de la duréc des brovets, l'établissement d'une taxe progressive, la suppression de l'exception de possession personnclle, l'attribution de compétence aux tribunaux de commerce pour statuer dans certaines hypothèses sur les questions de brevets.

$$
\star^{*} \star
$$

Délutvrance des Brevets. - Renforgement des pouvoms DE L'AUTORITÉ ADMINISTRATIVE EN MATIÈRE DE DÉt.IVRANCE JE BREVETS SANS ADMISSION DU SYSTEME DE L'EXAMEN PREALABLI: - Appelée à statuer sur les modifications qu'il y avait lieu d'apporter à la loi du 5 juillet 1844 , la Commission avait à examiner, dès le début de ses travaux, une première question fort importante qui domine la législation des brevets.

Faut-il maintenir en malière de délivrance de brevets le système de la loi de 1844 ?

Ce système s'analyse dans l'article in de la loi, aux termos duquel " les brevets sont délivrés sans examen préalable, a'ux

(1) La Houille Blanche de janvier 1913. 